\title{
Technological innovations to improve health outcome in type 2 diabetes mellitus: A randomized controlled study
}

\author{
D. Sunil Kumar a, B. Prakash ${ }^{\text {a }}$, B.J. Subhash Chandra ${ }^{\mathrm{b}}$, Padma Shrinivas Kadkol ${ }^{\mathrm{c}}$,

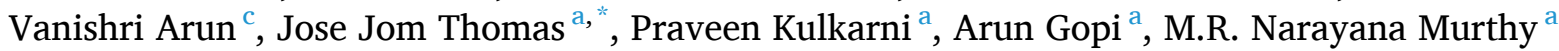

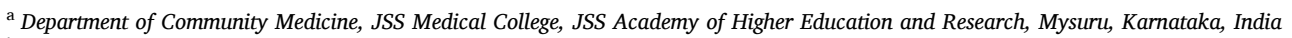 \\ ${ }^{\mathrm{b}}$ Department of General Medicine, JSS Medical College, JSS Academy of Higher Education and Research, Mysuru, Karnataka, India \\ ${ }^{\mathrm{c}}$ Department of Information Science \& Engineering, JSS S\&T University (Formally SJCE), Mysuru, India
}

\section{A R T I C L E I N F O}

\section{Keywords:}

Diabetes mellitus

m-Health

Mobile application

\begin{abstract}
A B S T R A C T
Introduction: Diabetes Mellitus is a major chronic disease associated with many complications and high morbidity. The need for lifestyle modification and regular adherent treatment makes the management of the disease difficult. This study examines the scope of $\mathrm{m}$-Health in the management of type 2 diabetes mellitus in terms of glycemic control.

Methods: A randomized controlled study was performed among the patients attending the outpatient department of a tertiary care hospital in Mysuru city. A mobile application named DIAGURU, mainly focusing on lifestyle modification and medication management was used for a period of 6 months from April 2019 to September 2019 by 150 patients in the study group while another 150 participants served as controls. The change in glycosylated haemoglobin levels was assessed after six months.

Results: The mean HbA1C levels at the starting of the study was found to be $7.36 \% \pm 1.04$ in the study group and $7.84 \% \pm 1.33 \%$ in the control group. A repeat HbA1c test after six months showed a mean level of $7.10 \% \pm$ $0.96 \%$ among the participants who received the intervention and $7.97 \% \pm 1.37 \%$ among the control group. The values were showing a trend of reduction in the intervention group, with a median reduction $\mathrm{HbA} 1 \mathrm{c}$ of $-0.2 \%$ $(-0.3 \%$ to $-0.2 \%)$. Among the participants who did not receive our intervention, a median increase of $0.1 \%$ $(0 \%-0.2 \%)$ in HbA1c was noticed. Mann Whitney $U$ test was performed, and it showed a statistically significant association with a p value less than 0.001 .

Conclusion: From this study, we conclude that an intervention with a mobile application aimed at lifestyle modification and medication management in addition to regular medical treatment for type 2 diabetes mellitus patients resulted in a better glycemic control compared to a control group who did not receive the adjuvant intervention. CTRI registration number: CTRI/2020/02/023115.
\end{abstract}

\section{Introduction}

A major concern of the current era, Type 2 diabetes mellitus (T2DM) is associated with several complications and high mortality. Enough evidence has been collected to prove that lifestyle interventions can prevent the development and further complications of T2DM in the susceptible population. ${ }^{1,2}$ To prevent the development of complications, treatment with multiple medications and permanent lifestyle changes are often required in diabetes mellitus. ${ }^{3}$ The glycosylated haemoglobin test (HbA1C) is a beneficial measure of average blood glucose levels over the previous three months. ${ }^{4}$ A glycosylated haemoglobin level of more than $6.5 \%$ is diagnostic of Diabetes Mellitus. ${ }^{5}$ Lifestyle modification is already proven to be a better and more cost-effective measure than medications for prevention and treatment of diabetes and its complications. However, such interventions are difficult to implement in practice due to the high cost of delivery of information by health experts in a face to face manner, the overwhelming workload in the health care setting, and lack coverage of such expenses in health insurance. ${ }^{6}$

Managing diabetes mellitus and adhering to the strict medication and lifestyle advises is a difficult task for the patients. It involves medication management, dosage adjustments, and blood sugar level tracking. Hence assistance is necessary to guide the patients in adhering to the medication and lifestyle modification. The mobile applications can assist the patients by giving nutritional advises, estimating carbohydrate content in the food

\footnotetext{
* Corresponding author.

E-mail address: josejom031@gmail.com (J.J. Thomas).
} 
consumed, tacking blood sugar levels and giving appropriate warnings, and giving alerts for medicine intake. ${ }^{7}$ The m-Health (mobile health) is an approach to clinical or public health through mobile devices like smartphones, personal digital assistants, monitoring devices and other wireless electronic devices. ${ }^{8-10}$ Mobile health technology is an excellent opportunity to address the inequitable distribution of health and health services, improve the access and heal care delivery, and provide continuous care, especially in chronic diseases. The m-health as a public health innovation can also facilitate the easy monitoring, surveillance and management chronic health conditions. ${ }^{11-16}$

This study attempts to assess the impact of a mobile application for lifestyle modification and medication management of diabetic patients in glycosylated haemoglobin levels over a period of six months in Mysuru city of southern India.

\section{Methodology}

The study was conducted as a two-arm (usual care and intervention) randomized controlled trial. Type II Diabetic patients visiting a Tertiary care Hospital who gave their consent to the study were recruited for the trial. A pilot study was conducted with a sample size of 30 in each arm (case and control), and the difference in $\mathrm{HbA1c}$ was noted in each group after the intervention with the mobile application for 3 months. The mean glycosylated haemoglobin levels were reduced from $7.36 \% \pm$ $1.05 \%-7.23 \% \pm 1.09 \%$ in the intervention group and the same was increased from $7.84 \% \pm 1.35 \%-7.97 \% \pm 1.39 \%$ The $\mathrm{HbA} 1 \mathrm{c}$ value in the case group was reduced by 0.13 units after the intervention. Assuming that as the main study considers the follow up after six months, the HbA1c would further get reduced by 0.26 units, with an effect size of 0.12 , power of $80 \%$, an alpha error of $5 \%$, a sample size of 135 was calculated in each group. Assuming a loss to follow up of $10 \%$, the sample size was adjusted to 150 in each group.

Participants were selected from the patients visiting the outpatient department of a tertiary care hospital in Mysuru city of southern India. Patients aged 18-65 years, diagnosed with type II Diabetes Mellitus more than one year ago, receiving treatment with insulin and/or oral hypoglycemic drugs and own an android Smartphone were included, and patients with severe complications, pregnant ladies and patients who were not capable of using a Smartphone application were excluded from the study. From the total 580 diabetic patients attended the OPD, first 300 patients attending the inclusion and exclusion criteria were selected. The participants were randomly allocated using sealed envelopes after stratifying based on gender. Random number table was used for randomization.

Ethical clearance for the study was obtained from Institutional ethics committee of the JSS Medical College, Mysore. The trial was initiated with the ethical committee clearance alone. However, a post-trial registration was obtained from the Clinical Trial Registry-India (CTRI), as the study fits into the WHO criteria for clinical trials. The CTRI registration number for the trial is CTRI/2020/02/023115. After obtaining informed consent, details regarding socio-demographic characteristics, family history of diabetes, dietary patterns, physical activities, and tobacco and alcohol consumption were collected from each study participant using a pre-tested structured questionnaire by interviewing each subject. Patients in both the groups were asked to continue with their usual care, as a visit to their primary diabetes health care practitioner. Additionally, patients allocated to the study group were given instructions to download the android Smartphone application named 'Diaguru', which was developed by the research team. The app provided the users with a simple interface having many features to help them in the management of diabetes through smartphones. The values of the sugar level, insulin level and the type of food intake could be given as input. The app was automated to alert the user if the values were not in the normal range. The

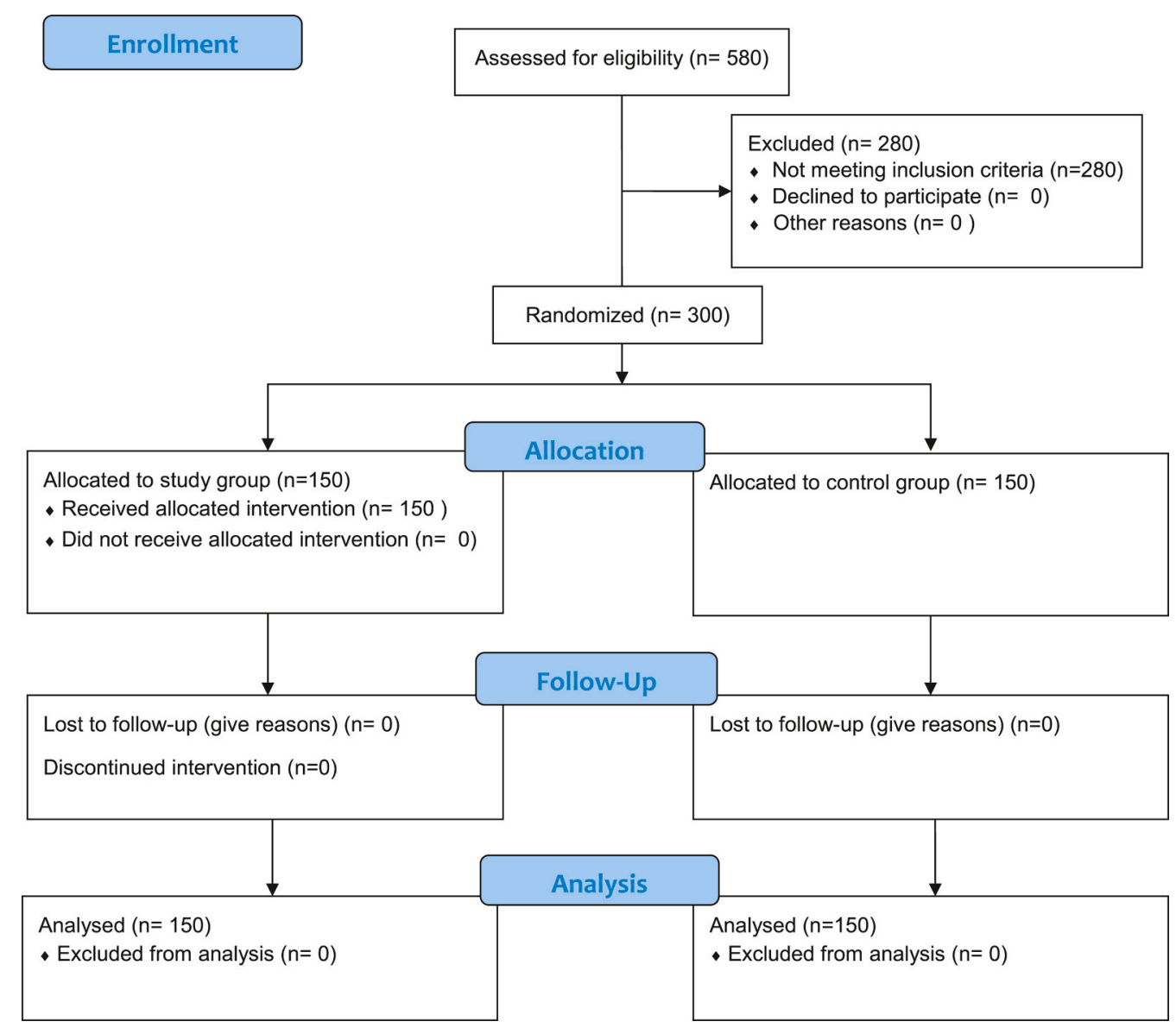

Fig. 1. CONSORT 2010 Flow Diagram showing enrollment, allocation and follow up of the study participants. 
prescription given by the Doctor was stored using the app and was programmed to notify the user to take medicines on time. The caloric value of the food intake could be computed when the user selects the type of food he had consumed, which were available under the categories such as breakfast, lunch, snacks and dinner. Based on his sugar level and the caloric count, the user was to be advised about the calories he required to take in a day. Reports and graphs were generated by the application to give them a clear idea of blood sugar levels. The app also answered FAQs and provided tips and references. The initial evaluation of study participants was done during the months of March and April. The participants in the intervention arm used the mobile application for a period of 6 months from April 2019 to September 2019. An end-line assessment was done during the monthly visit to OPD in September and October 2019 to evaluate the effectiveness of the Smartphone-based health application in the management of type II Diabetes Mellitus. The outcome measure was the change in glycemic control by assessing the HbA1c levels. Fig. 1 shows the CONSORT 2010 Flow Diagram showing enrollment, allocation and follow up of the study participants.

Data collected were entered in MS-Excel - 2010 and analyzed using a licensed version of SPSS version 22. Descriptive statistical measures like percentages, mean, median and standard deviation were applied.

Table 1

Demographic characteristics of the study participants in the intervention group and control group.

\begin{tabular}{|c|c|c|c|c|c|}
\hline \multirow{2}{*}{\multicolumn{2}{|c|}{$\begin{array}{l}\text { Demographic/Personal } \\
\text { Characteristics }\end{array}$}} & \multicolumn{2}{|c|}{ Study Group } & \multicolumn{2}{|c|}{ Control Group } \\
\hline & & \multirow{2}{*}{$\begin{array}{l}\text { Number } \\
90\end{array}$} & \multirow{2}{*}{$\begin{array}{l}\text { Percentage } \\
60\end{array}$} & \multirow{2}{*}{$\begin{array}{l}\text { Number } \\
90\end{array}$} & \multirow{2}{*}{$\begin{array}{l}\text { Percentage } \\
60\end{array}$} \\
\hline Gender & Male & & & & \\
\hline & Female & 60 & 40 & 60 & 40 \\
\hline \multirow{5}{*}{$\begin{array}{l}\text { Type of } \\
\text { family }\end{array}$} & Nuclear family & 100 & 66.6 & 135 & 90 \\
\hline & Joint Family & 40 & 26.7 & 15 & 10 \\
\hline & Three & 10 & 6.7 & 0 & 0 \\
\hline & Generation & & & & \\
\hline & Family & & & & \\
\hline \multirow[t]{2}{*}{ Diet } & Vegetarian Diet & 35 & 23.3 & 105 & 70 \\
\hline & Mixed Diet & 115 & 76.7 & 45 & 30 \\
\hline
\end{tabular}

Table 2

Distribution of study participants based on educational and occupational status.

\begin{tabular}{|c|c|c|c|c|c|}
\hline \multicolumn{2}{|c|}{ Demographic Characteristics } & \multicolumn{2}{|c|}{ Study Group } & \multicolumn{2}{|c|}{ Control Group } \\
\hline & & Number & Percentage & Number & Percentage \\
\hline \multirow{4}{*}{$\begin{array}{l}\text { Educational } \\
\text { Status }\end{array}$} & $\begin{array}{l}\text { Primary } \\
\text { School }\end{array}$ & 5 & 3.3 & 20 & 13.3 \\
\hline & $\begin{array}{l}\text { Secondary } \\
\text { School }\end{array}$ & 10 & 6.7 & 90 & 60 \\
\hline & $\begin{array}{l}\text { Post High } \\
\text { School } \\
\text { Diploma }\end{array}$ & 10 & 6.7 & 30 & 20 \\
\hline & Graduates & 125 & 83.3 & 10 & 6.7 \\
\hline \multirow[t]{3}{*}{ Occupation } & Skilled Work & 0 & 0 & 5 & 3.3 \\
\hline & Business & 115 & 76.7 & 95 & 63.3 \\
\hline & Housewife & 35 & 23.3 & 50 & 33.3 \\
\hline
\end{tabular}

Inferential statistical tests like paired sample $\mathrm{T}$ test was done to assess the significance in difference of HbA1c change in study group and control group. The differences were interpreted as statistically significant at $\mathrm{P}<0.05$. Data were presented as tables as relevant.

\section{Results}

The mean age of the study participants in the study group was 55.73 \pm 10.45 years, while the mean age of the participants in the control group was $73.56 \pm 11.27$ years. Both the groups were composed of 90 $(60 \%)$ males and $60(40 \%)$ females. Among the group of patients who used the mobile application 100 (66.6\%) belonged to nuclear families, 40 (26.7 belonged to joint families, and $10(6.7 \%)$ belonged to threegeneration families. In the control group of patients, the majority $(135,90 \%)$ were from nuclear families, while the remaining $10 \%$ were from joint families. All the patients in both groups were residents of urban areas and had an economic status above the poverty line. Majority in the study group were following a mixed diet (76.7\%) while vegetarians were predominant in the control group (70\%) (Table 1).

Among the participants in the study group, 5 (3.3\%) were primary school educated, $10(6.7 \%)$ were educated till secondary school, 10 (6.7\%) had a diploma and $125(83.3 \%)$ were graduates. In the control group, $20(13.3 \%)$ were primary school educated, 90 (60\%) were secondary school educated, $30(20 \%)$ had a diploma and $10(6.7 \%)$ were graduates. Of the 150 participants in the study group, 115 (76.7\%) were doing business, and 35 (23.3\%) were housewives. In the control group, 5 (3.3\%) were skilled workers, 95 (63.3\%) were doing business, and 50 (33.3\%) were housewives (Table 2).

Among the 150 participants in the study group, 85 (56.7\%) were on oral hypoglycemic agents during the study. While 45 (30\%) were taking regular insulin, 20 (13.3\%) were taking both insulin and oral hypoglycemic agents to control diabetes mellitus. In the control group, 70 (46.7\%) were taking oral hypoglycemic agents, 45 (30\%) were taking insulin, and 35 (23.3\%) were taking both insulin and oral hypoglycemic agents. The median duration of diabetes mellitus among participants in the study group was eight years with an interquartile range of 4-12 years while the median duration of illness among the participants in the control group was ten years with an interquartile range of 8-18 years. Hypertension was a co-morbidity in $45(30 \%)$ participants in the study group and $80(53.3 \%)$ participants in the control group. Of the 150 samples in the study group, 55 (36.7\%) were consuming alcohol and 25 (16.7\%) were smokers. In the control group, $20(13.3 \%)$ participants were consuming alcohol, and 10 (6.7\%) participants were smokers (Table 3).

The mean HbA1C levels at the starting of the study were found to be $7.36 \% \pm 1.04$ in the study group and $7.84 \% \pm 1.33 \%$ in the control group. A repeat HbA1c test showed a mean level of $7.10 \% \pm 0.96 \%$ among the participants who received the intervention and $7.97 \% \pm$ $1.37 \%$ among the control group. The values were showing a trend of reduction in the study group, and increase in the control group. Paired T test was performed, and it showed a statistically significant association with a $\mathrm{p}$ value of 0.001 in both the groups (Table 4).

Table 3

The medical history of study participants in the intervention and control group.

\begin{tabular}{|c|c|c|c|c|c|}
\hline \multirow[t]{2}{*}{ Medical History } & & \multicolumn{2}{|c|}{ Study Group } & \multicolumn{2}{|c|}{ Control Group } \\
\hline & & Number & Percentage & Number & Percentage \\
\hline \multirow[t]{3}{*}{ Current Treatment for Diabetes Mellitus } & Oral Hypoglycemic Agents & 85 & 56.7 & 70 & 46.7 \\
\hline & Insulin & 45 & 30 & 45 & 30 \\
\hline & Both combined & 20 & 13.3 & 35 & 23.3 \\
\hline \multirow[t]{2}{*}{ Hypertension } & Present & 45 & 30 & 80 & 53.3 \\
\hline & Absent & 105 & 70 & 70 & 46.7 \\
\hline \multirow[t]{2}{*}{ Alcohol Use } & Present & 55 & 36.7 & 20 & 13.3 \\
\hline & Absent & 95 & 63.3 & 130 & 86.7 \\
\hline \multirow[t]{2}{*}{ Tobacco Use } & Present & 25 & 16.7 & 10 & 6.7 \\
\hline & Absent & 125 & 83.3 & 140 & 93.3 \\
\hline
\end{tabular}


Table 4

The HbA1c levels of study participants before and after the intervention period.

\begin{tabular}{|c|c|c|c|c|}
\hline Groups & HbA1c & Mean & Std. Deviation & $\mathrm{p}^{*}$ \\
\hline \multirow[t]{2}{*}{ Study Group } & Before & 7.36 & 1.04 & \multirow[t]{2}{*}{0.001} \\
\hline & After & 7.10 & 0.96 & \\
\hline \multirow[t]{2}{*}{ Control Group } & Before & 7.84 & 1.33 & \multirow[t]{2}{*}{0.001} \\
\hline & After & 7.97 & 1.37 & \\
\hline
\end{tabular}

\section{Discussion}

Our study thus shows better glycemic control among participants who received a smartphone application intervention for medication management and lifestyle modification. Similar studies and systematic reviews also show improved glycemic control among patients who received similar interventions. Morwenna Kirwan et al. showed a marked decrease in hbA1c levels in patients who used a similar mobile application for six months. The participants who received the intervention showed a mean reduction hbA1c from $9.08 \% \pm 1.18-7.80 \% \pm$ 0.75 while control grouped showed an increase in HbA1C levels after nine months. $(8.47 \% \pm 0.86-8.58 \% \pm 1.16) .{ }^{17}$ A quasi-experimental study was performed in Chicago by Shantanu Nundy et al. among diabetic patients demonstrated an average reduction of $\mathrm{Hba} 1 \mathrm{c}$ from $7.9 \%$ to $7.2 \%$ over six months using a similar application. ${ }^{18}$

A meta-analysis performed by Can Hou et al. compared the results of 14 studies from 1996 to 2015 and showed better glycemic control among diabetic patients used mobile applications as an adjuvant to medical therapy. A mean reduction of $0.49 \%$ HbA1c was observed among intervention groups compared to control groups. ${ }^{19}$ Another systematic review and meta-analysis of 13 studies show an overall reduction in Hba1c levels among intervention groups who used mobile applications for lifestyle modification and medication management. Among the 13 studies evaluated in the meta-analysis, six studies, showed a statistical difference in reduction Hba1c levels similar to our study. ${ }^{20}$

$\mathrm{X}$ Liang et al. analyzed 22 trials from various parts of the world and showed that mobile phone application for self-management of diabetes mellitus reduced $\mathrm{HbA} 1 \mathrm{c}$ values by a mean of $0.5 \%$ [ $6 \mathrm{mmol} / \mathrm{mol} ; 95 \%$ confidence interval, $0.3-0.7 \%(4-8 \mathrm{mmol} / \mathrm{mol})]$ over a median of 6 months follow-up duration. ${ }^{21}$

Thus the literature available coincides with the findings of our study proving a significantly better glycemic control among type II diabetic patients who use mobile applications intended for lifestyle modifications and medication management in addition to the regular treatment.

\section{Conclusion}

From this study, we conclude that an intervention with a mobile application aimed at lifestyle modification and medication management in addition to regular medical treatment for type 2 diabetes mellitus patients resulted in a better glycemic control compared to a control group who did not receive the adjuvant intervention. Thus evidencebased technological approach can serve as a model for the upcoming national programs for the policymakers in management of type 2 diabetes mellitus.

\section{Declaration of competing interestCOI}

The authors have no conflicts of interest.

\section{Ethical approval}

All procedures performed in studies involving human participants were in accordance with the ethical standards of the institutional ethical committee and with the 1964 Helsinki declaration and its later amendments or comparable ethical standards.

\section{Informed consent}

Informed consent was obtained from all individual participants included in the study "The authors confirm that all ongoing and related trials for this drug/intervention are registered."

\section{Acknowledgement}

We acknowledge the Department of community medicine, JSS Medical College Mysuru for the support, Outpatient department, JSS Hospital for the permission to conduct the study and the Department of Information Science and Engineering, JSS S\&T University (Formally SJCE) for helping us in developing the mobile application. We also thank the study participants for their cooperation.

\section{References}

1 Tuomilehto J, Lindstrom J, Eriksson JG, et al. Prevention of type 2 diabetes mellitus by changes in lifestyle among subjects with impaired glucose tolerance. $N$ Engl J Med. 2001;344:1343-1350.

2 Knowler WC, Barrett-Connor E, Fowler SE, et al. Reduction in the incidence of type 2 diabetes with lifestyle intervention or metformin. N Engl J Med. 2002;346:393-403.

3 Gaede P, Lund-Andersen H, Parving HH, Pedersen O. Effect of a multifactorial intervention on mortality in type 2 diabetes. $N$ Engl J Med. 2008;358:580-591.

4 Types of diabetes mellitus. Available from: the url http://www.webmd. $\mathrm{com} /$ diabetes/guide/types-of-diabetes-mellitus?page $=2 \#$.

5 International Expert Committee. International Expert Committee report on the role of the A1C assay in the diagnosis of diabetes. Diabetes Care. 2009;32(7):1327-1334.

6 Katula JA, Blackwell CS, Rosenberger EL, Goff Jr DC, Healthy Living Partnerships to Prevent Diabetes Research Team. Translating diabetes prevention programs: implications for dissemination and policy. N C Med J. 2011:724058.

7 Smartphone apps for diabetes: do they really work?. Available from: the url http://co nsumer.healthday.com/diabetes-information-10/blood-glucose-monitor-news69/smartphone-apps-for-diabetes-do-they-really-work-684002.html.

8 World Health Organization. m-Health New horizons for health through mobile technologies. In: Global Observatory for eHealth Series-Volume 3 [serial Online]; 2011 [cited 2014 Jan 18]; Switzerland: Geneva. Available from: www.who.int/goe/publ ications/goe_m-Health_web.pdf.

9 Yan H, Huo H, Xu Y, Gidlund M. Wireless sensor network based E-health system-implementation and experimental results. IEEE Trans Consum Electron. 2010;56(4):2288-2295.

10 Hernandez AI, Mora F, Villegas M, Passariello G, Carrault G. Real-time ECG transmission via internet for nonclinical applications. IEEE Trans Inf Technol Biomed. 2001;5(3):253-257.

11 Marshall A, Medvedev O, Antonov A. Use of a smartphone for improved selfmanagement of pulmonary rehabilitation. Int J Telemed Appl. 2008.

12 Charpentier G, Benhamou P-Y, Dardari D, et al. The diabeo software enabling individualized insulin dose adjustments combined with telemedicine support improves $\mathrm{HbA1c}$ in poorly controlled type 1 diabetic patients: a 6-month, randomized, open-label, parallel-group, multicenter trial (TeleDiab 1 study). Diabetes Care. 2011;34:533-539.

13 Worringham C, Rojek A, Stewart I, Miranda JJ. Development and feasibility of a smartphone. ECG and GPS based system for remotely monitoring exercise in cardiac rehabilitation. PloS One. 2011;6, e14669.

14 Ryan D, Cobern W, Wheeler J, Price D, Tarassenko L. Mobile phone technology in the management of asthma. $J$ Telemed Telecare. 2005;11:43-46.

15 Bexelius C, Löf M, Sandin S, Lagerros YT, Forsum E, Litton JE. Measures of physical activity using cell phones: validation using criterion methods. J Med Internet Res. 2010;12:1-15.

16 Boulos MNK, Wheeler S, Tavares C \&Jones R. How smartphones are changing the face of mobile and participatory healthcare: an overview, with example from eCAALYX. Biomed Eng Online. 2011;10:24.

17 Kirwan M, Vandelanotte C, Fenning A, Duncan MJ. Diabetes self-management smartphone application for adults with type 1 diabetes: randomized controlled trial. $J$ Med Internet Res. 2013;15(11):e235.

18 Nundy S, Dick JJ, Chou CH, Nocon RS, Chin MH, Peek ME. Mobile phone diabetes project led to improved glycemic control and net savings for Chicago plan participants. Health Aff. 2014 Feb 1;33(2):265-272.

19 Hou C, Carter B, Hewitt J, Francisa T, Mayor S. Do mobile phone applications improve glycemic control (HbA1c) in the self-management of diabetes? A systematic review, meta-analysis, and GRADE of 14 randomized trials. Diabetes Care. 2016 Nov 1;39(11):2089-2095.

20 Bonoto BC, de Araújo VE, Godói IP, et al. Efficacy of mobile apps to support the care of patients with diabetes mellitus: a systematic review and meta-analysis of randomized controlled trials. JMIR mHealth $u$ Health. 2017;5(3):e4.

21 Liang X, Wang Q, Yang X, et al. Effect of mobile phone intervention for diabetes on glycaemic control: a meta-analysis. Diabet Med. 2011 Apr;28(4):455-463. 